\title{
PRIMAVERA DEL ROMANCERO NUEVO EN PORTUGAL
}

Entre las formas métricas tradicionales en la poesía ibérica, la más cultivada desde la Edad Media es, sin duda, el romance. Su evolución a lo largo del siglo xvi puede seguirse a través de composiciones anónimas o de autores conocidos, precursores de la renovación del romancero ocurrida en los últimos veinte años de aquel siglo, gracias a una nueva generación poética que, innovando temas y morfología, le abre una nueva etapa que durará hasta mediados del siglo xvir. Es entonces cuando el romancero acusa ya una fatiga que lo sumirá en un lento crepúsculo, rasgado apenas de fugaces destellos, que durará más de un siglo.

Poco importaba ya, cuando detrás quedaba esa sorprendente floración del llamado Romancero nuevo o, con menos acierto, artístico, que tiene lugar en España hacia 1580, aunque no alcanza su más amplia difusión y popularidad hasta 1589 , al divulgarse en folletos y libros, como la Flor de varios romances nuezos, cuyas nueve partes se verterán en el Romancero General de 1600.

Es aproximadamente entre el tramontar de la primera mitad del siglo Xvi y la fecha convencional de 1580 cuando comienzan a percibirse los primeros tanteos de renovación del romancero. Este estadio intermedio o período de transición del romancero tradicional al nuevo tiene también su paralelo en Portugal, que sigue, paso a paso, el experimento de los poetas españoles, aunque con extrema penuria artística y numérica, pese a la afirmación en contrario de Carolina Michaëlis, que habla de la "infinidade de romances compostos por letrados portugueses, de $1550 \mathrm{em}$ adianten ' ${ }^{1}$. Si hubiera propuesto el año de 1596, y ya veremos por qué,

1 Estudos sobre o romanceiro peninsular. Romances velhos em Portugal. Coimbra, 1934, pág. 242. 
no habría ninguna objeción que oponerle, pero, mientras no se demuestre lo contrario, la fecha de 1550 me parece completamente arbitraria, porque, entre ese año y el de 1596, no son muchos los romances que pueden reunirse, y de muy dudosa calidad artística. En cambio, a partir de esta ́ultima fecha, o poco antes, sí comienzan a encontrarse poetas portugueses que, imitando fielmente a sus modelos castellanos, aclimatan también en Portugal cl romancero nuevo $y$, ahora, con logros positivos.

ROMANCISTAS, POE'TAS DE LUSITANIA

De esos "letrados portugueses», como les llama doña Carolina, los más de ellos autores de un solo romance, como Pedro de Andrade Caminha y Manuel de Portugal, es André Falcão de Resende el mejor representado, al menos por el número: cinco romances noticieros que nos informan desde la jornada de Carlos V a Viena, en 1523, a la batalla de las Ilhas Terceiras, en 1691, entre una escuadra española $y$ otra inglesa, pasando por la victoria de Lepanto, una fiesta de toros en el Madrid de Felipe II y la entrada de este rey en Lisboa, en 1581. Excepto el primer romance, los otros son meros reportajes compuestos, sin duda, a raíz de los sucesos en ellos reseñados, y todos muy en los aledaños del triunfo del romancero nuevo, con el que sólo tienen relación temporal, porque estilísticamente caen del otro lado de la valla ${ }^{2}$.

Los cinco romances de Falcão de Resende están escritos en castellano, lengua que utilizarán de preferencia los poetas portugueses que introducen en su país el cultivo del nuevo romancero. Los que les siguen en el siglo XVII, también. La cosa parece obvia desde nuestra perspectiva. Por una parte, el cultivo del castellano en Portugal estaba llegando a su apogeo; por otra, los modelos de los romancistas portugueses eran, como queda dicho, los que triunfaban en Castilla y se difundian por toda la Península en cartapacios, impresos o en el aire de la canción. Romances de Irope de Vega, de Iruis de Góngora, de Pedro Liñán de Riaza, de Juan de Salinas $y$ otros de menor nombradía, de los que se tomaba la lengua, los temas, el estilo, todo.

Son precisamente los nombres de Lope, Góngora, Liñán y Salinas, y bien sabemos que no podían ser otros ${ }^{3}$, los que cita Francisco Rodrigues

2 Pueden leerse en D. Garcia Peres : Catálogo... de los autores portugueses que escribieron en castellano. Madrid, 1890, págs. 161-202.

3 Espinel no tiene para nosotros, hoy, como romancista, la importancia que parece atribuirle Rodrigues Lobo. 
Lobo en la tantas veces aireada "Carta aos Romancistas de Portugal", con que abre la primera parte de sus Romances:

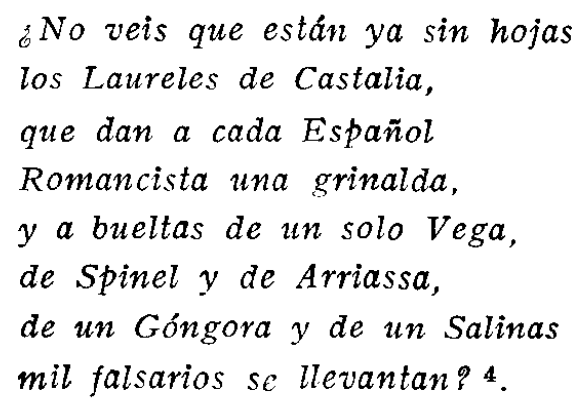

Pero, a vueltas de esos nombres ilustres, Rodrigues Lobo alude cla-

4 Cito por Primeyra e Segunda Parte dos Romances (Coimbra, 1596), ed. de A. PÉRtz y Gómez. Colecrión Duque y Marqués. «... la fonte que mana y corre...n. Valencia, 1960.

En el romance con que comienza la Segunda parte («Espérese un poco Azarque, / tenga la rienda al cavallon), Rodrigues Lobo vuelve a la carga contra esos (mil falsarios», cuyo número ha crecido ahora alarmantemente:

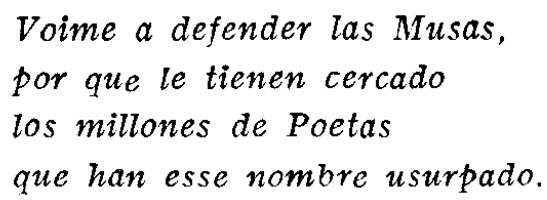

Y más adelante declara sus preferencias poéticas, portuguesas y castellanas, al citar a Franco (Bernardim Ribeiro), Frondelio (Camões), Riselo (Liñán) y Belardo (Lope) :

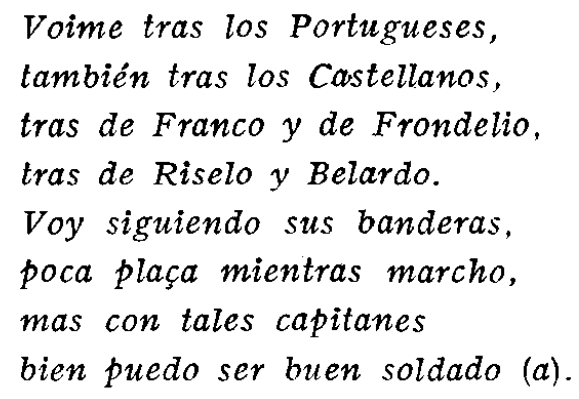

(a) Todos los textos que se citan en este trabajo se reproducen respetan. do lusismos y grafías, sin más modificación que regularizar el uso de $u \mathrm{y} v$, deshacer las abreviaturas $\mathrm{y}$ modernizar la acentuación y puntuación. 
ramente a otros poetas portugueses coetáneos que parece celar el más impenetrable misterio y que son, justamente, a quienes dirige su "Carta":

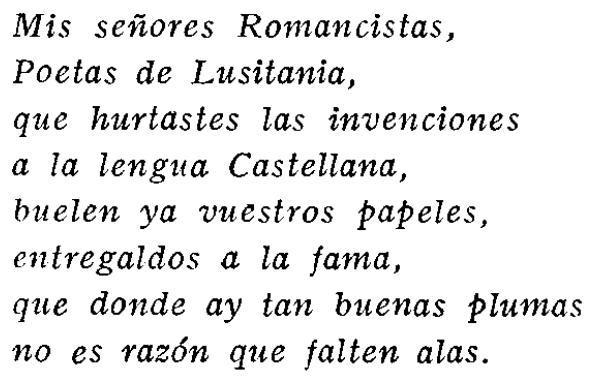

¿Quiénes eran estos romancistas lusitanos que, después de hurtar las invenciones a la lengua castellana, parecían remisos a entregar a la fama los frutos de su ingenio poético? Existían; Rodrigues Lobo nos lo dice sin lugar a dudas. Mas para explorar esa laguna -rumor de aguas invisibles- será precisa mucha paciencia y un buceo muy hondo en las colecciones manuscritas de finales del siglo xvr, que, sospecho, no aclararán gran cosa en lo que a nombres se refiere ${ }^{5}$.

¿Y las colecciones impresas? E1, por lo general, impenetrable anonimato de los romanceros publicados en los f́ltimos años del siglo xvI hace poco menos que imposible saber si sus páginas fueron abordables a poetas portugueses. Rodrigues Lobo, que podría estar en el secreto, parece ignorarlo también, al menos eso es lo que se desprende de unos versos de la citada "Carta" :

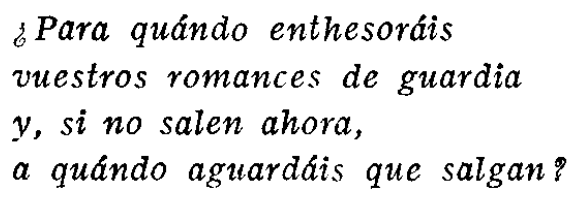

Pero sí salían, habían salido ya algunos. ¿Cuántos? ¿Muchos? ¿Po$\cos$ ? Aquí volvemos a sumirnos en el esquivo anonimato de los romanceros; pero, indudablemente, más de una de las Flores de romances arropó, en sus páginas, "papeles" de vates lusitanos, y, hasta en tres ocasiones, se nos descubre el nombre de uno de ellos. Se trata del hasta ahora desconocido Agustín de Paredes, "Lusitano", según reza una de las rúbricas de los tres romances que, a su nombre, publica, en 1593, el librero Pedro

5 Los romances de Simón Garcia de Brito, por ejemplo, que publica Garcra PERES : Catálogo, págs. 259-271, me parecen de época posterior a la que aquí se trata. 
de Flores, en la Sexta parte de su Ramillete de Flores. Parece ser que este librero estaba establecido en Lisboa, donde da a la prensa este volumen, que continúa la serie de la Flor de Romances nuevos ${ }^{6}$. Es natural que, en estas circunstancias, Flores hiciese alguna concesión al público portugués e incluyese, al lado de Lope, Góngora, Liñán y otros algún poeta lusitano. La suerte le tocó, no sabemos por qué extraños designios, a este Agustín de Paredes, del que no he hallado más rastros que los deparados por el Ramillete, donde está representado, con toda saguridad. por tres romances moriscos.

El primero, romance de salida ( Çayde por nombre tienen) y amores contrariados, es el que comienza:

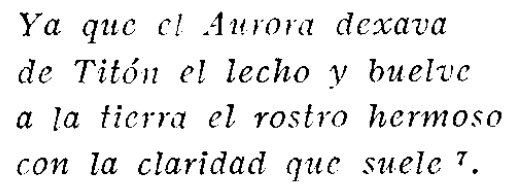

y continúa en el siguiente :

Fixos 8, pues, Çayde los ojos, tan alegres qual conviene, por ser el tiempo cumplido de su tan propicia sucrte 9 .

E1 tercero, y el mejor, es romance de celos :

$$
\begin{aligned}
& \text { La mañana de san Juan } \\
& \text { salen a coger guirnaldas, } \\
& \text { Zara, muger del Rey chico, } \\
& \text { con sus más queridas damas } 10 .
\end{aligned}
$$

6 Ramillete de Flores. / Quarta, / Quinta, y Sexta parte de Flor do Romances nueuos, nunca hasta / agora impressos, llamado, Rami- I llete de Flores: De muchos, gra- / ues y diuersos Autores, Recopi. / lado no có poco trauaio Por / Pedro Flores Librero: I Y a su costa im- / presso. / Y demas desto, wa al cabo la / ter cera parte de el Araucana, en / nucue Romances, excepto la cntra- / da de este Reyno de Portugal, a por / ser tan notoria a todos no se pone. / Con Licencia, y Priuilegio. / En Lisboa, / Por Antonio Aluarez Impressor. / Año de 1593. / Vendese en casa de el mismo / Flores, al Pelourinho Velho.

Véase ahora la edición, por la que cito, de $\Lambda$. Rodríguez Moñino, tomios V, VI y VII de Las Fuentes del Romancero General (Madrid, 1600). Madrid, 1957.

7 "Otro romance de çayde, hecho por Agustín de Paredes», ed. cit., fol. 394.

8 "Fixó» en el Romancero General de 1600, fol. 202 v.

9 "Otro del mismo Paredes», fol. 396.

10 «Romance hecho por Agustín de Paredes Lusitano», fol. 400. 
Entre éste y el segundo figura otro romance, anónimo, de la misma serie ("Çayde ha prometido fiestas / a las damas de Granada", fol. 398), que bien pudiera ser del mismo Paredes ${ }^{11}$.

$¿$ Hay otros romances de autores portugueses en el Ramillete de Flores? En el estado actual de la cuestión es imposible afirmarlo, pero no sugerir la posibilidad de que existan. José F. Montesinos señala, en el artículo que dedicó al Ramillete, cómo Pedro de Flores no descuidó la inclusión de romances relacionados, de algún modo, con la historia de Portugal y asociados otros a sucesos locales ${ }^{12}$. En efecto, en la Cuarta parte del Ramillete se reúnen seis romances concernientes a Portugal y que bien podrían ser de autoría portuguesa, así el que comienza :

$$
\begin{aligned}
& \text { Aquel mayoral gallardo } \\
& \text { que governava el exido, } \\
& \text { del Lusitano contorno } \\
& \text { çagal dispuesto y luzido }{ }^{13} \text {. }
\end{aligned}
$$

en el que hay referencias a una Delia, "luz del Lusitano abrigo", que, posiblemente, ocultaría, como era costumbre en el convencionalismo pastoril, a alguna conociḍa dama portuguesa.

Otra dama de la misma nacionalidad aparece, en el romance del folio 75 vuelto, presenciando la partida de la escuadra de don Sebastián, en la que va su enamorado:

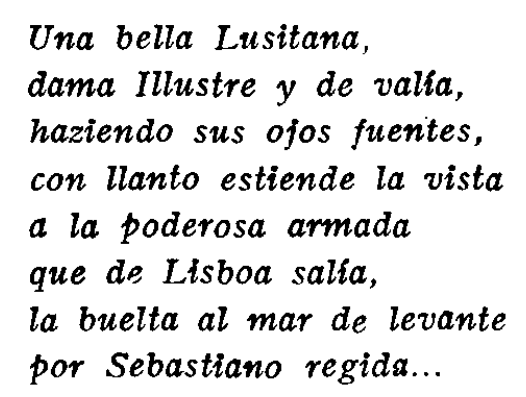

11 Sobre este romance dice José F. Montesinos : $\propto$ El figurar entre romances de Paredes y pertenecer a la misma serie no fuerza la conclusión de que sea obra del mismo poeta, pero la hace verosímil.» Vid. Algunas notas sobre el romancero «Ramillete de flores», en NRFH, 1952, VI, pág. 377.

Para otros problemas planteados por la recopilación de Pedro de Flores, véase Damien SAUNal: Une pseudo-source $d u$ «Romancero Generaln: le «Ramillete de Flores», en Mélanges offerts à Marcel Bataillon. Bordeaux, 1962, págs. 644-665.

12 Art. cit., pág. 357.

13 "Otro en respuesta de la partida del romance de arriba», ed. cit., fol. $21 \mathrm{v}$. El romance de arriba, o inmediatamente anterior, es «Una gallarda pastora», fol. 20. 
E1 que sigue, "Romance sobre la muerte del capitán Aldana en Africa) ("De la sangrienta batalla / que tuvo el Rey Sebastiano», fol. 77), parece pertenecer, como el anterior y otros ${ }^{14}$, a un ciclo sebastiánico, en el que se canta la desdichada expedición a Africa. A pesar de la rúbrica, es de la muerte del rey y no de la de Aldana, además de un vehemente diálogo entre ambos, de lo que trata el romance, que termina:

pero la Parcha cruel,
que tiene el cuchillo alçado,
a Sebastiano dio muerte
y a su Reyno eterno llanto.

A continuación se recoge otro romance histórico sobre la "Entrada en Lisboa por el Conde don Alfonso Enríquez, primero Rey de Portugal» ("Quando el Conde Alfonso Enríquez, / primer Rey de Portugal», fol. 79), que trata de la entrega pacífica de Lisboa por el rey moro que la poseía y su conversión al cristianismo. Forma intencionada pareja con éste el siguiente "Romance de la entrada en Lisboa por el Rey don Phelippe" :

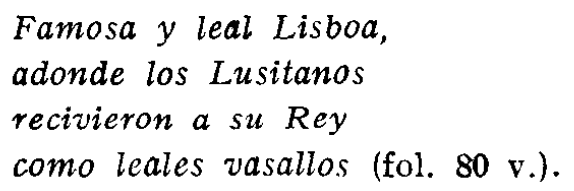

Sigue un romance fronterizo de la guerra de Granada ("A vista de los dos Reyes / Ysabel y don Fernando", fol. 82), en el que luchan un moro y un cristiano, "mancebo y floreciente / y de nación Lusitano", que declara con énfasis :

$y$ del Rey Don Juan segundo
soy y seré su vassallo,
soy don Francisco de Almeyda
en mi patria bien nombrado ${ }^{15}$.

Volvemos a encontrar a este personaje en el "Romance y suceso de don Francisco de Almeyda, Capitán de Arzilan, de tema fronterizo africano ((El gallardo moro Homar, / que en Africa residía), fol. 142 v.).

14 Como indica en nota el Ramillete, en la Tercera parte de Flor de varios romances, recopilados por PEDro DE Moncayo, Madrid, 1593, fol. 156, vol. III de Las Fuentes del Romancero, hay otro romance del mismo ciclo: «Discurriendo en la batalla l: el Rey Sebastiano el bravo».

15 Lo era, en efecto, y en 1505 se le nombró primer virrey de la India. 
Una batida menos precipitada que esta mía deparará probablemente nuevas piezas en las otras partes de la Flor de varios romances. Queda para otra ocasión. Ahora vamos a ver qué portugueses se libraron de la anonimia de los romanceros colectivos, donde parece no tuvieron acogida, dándose a conocer en ediciones particulares. En este aspecto, el primero cronológicamente es Francisco Rodrigues Lobo (¿1580?-1621), que, en 1596, tres años después de salir a luz el Ramillete de Flores, publica su Primeyra e Segunda Parte dos Romances, que ya estaban escritos a comienzos de 1595, pues las licencias del libro son de septiembre y octubre de ese año. A fines de 1596 - las licencias son de marzo y octubre - aparecen las Rimas de Vasco Mousinho de Quevedo e Castel-Branco (vivía aún en 1619) ${ }^{16}$, y, al año siguiente, la Silvia de Lysardo, que la tradición viene atribuyendo a Fr. Bernardo de Brito, en el mundo Baltasar de Brito e Andrade (1568-1617) ${ }^{17}$. E1 más nutrido, en lo que a romances se refiere, es el libro de Rodrigues Lobo, con 59 piezas (54 en castellano, una bilingüe y cuatro en portugués) ${ }^{18}$; el de Mousinho tiene 26 (20 en castellano y seis en portugués), y el de Brito tiene 10, todos en castellano. A esto se reduce, por ahora, la aportación impresa de aquel momento.

Hay, sin embargo, otro libro de autor portugués que, aunque publicado fuera de Portugal y en fecha ligeramente posterior a los citados, quizá no sea del todo improcedente incluirlo en este lugar, por lo que tiene de común con ellos y, en general, en temas y estilo, con la primera etapa del romancero nuevo. Me refiero al Libro de varios sonetos, romances, cartas y décimas, de Antonio de Melo, impreso en Módena, en 1603, $y$ en el que se recogen 23 romances en castellano ${ }^{19}$. Y la inclusión aquí

16 Discurso sobre / a vida, e morte, de / Santa Isabel Rainha de / Portugal, $\mathcal{F}$ outras varias Rimas. / Por Vasco Mousinho de Castelbranco. / Dirigido ao Excellentissimo Senhor Duque, Dom / Aluaro de Lancastre. / [Escudo] / Impresso com licença do Sancto Officio. E del Rey. / Em Lisboa / Por Manoel de Lyra, anno de 1596. / A custa de Esteuão Lopez mercador de liuros.

17 Silvia / de Lysardo / em que ha varios So- / netos, \& Rimas com a segunda p.te / do sonho de Chrisfal / [grabado] / Agora novamente im- / pressa, \& posta em ordem, por Alexan- / dre de Siqueira, Impressor de liuros. / Em Lisboa, / Com licença, \& Priuilegio, 1597.

18 Sabido es que RODRIGUES LoBo incluyó también unos nueve romances, pastoriles y piscatorios, en su trilogía novelística $A$ Primavera, $O$ Pastor Peregrino y o Desenganado, las tres impresas en Lisboa en 1601, 1608 y 1614, respectivamente, y que es autor de La Jornada que la Magestad Católica del Rey Felipe III hizo a Portugal el año de 1619, Lisboa, 1623, compuesta de 56 romances en castellano.

19 Cito por la edición de A. Pé́rez y Gómez. Colección Duque y Marqués. «... la fonte que mana $\mathrm{y}$ corre...». Valencia, 1955. 
de este desconocido poeta $^{20}$ parece justificarse aún más si tenemos en cuenta que uno de sus romances, el que comienza "Mientras se apresta Ximena / con algunos de los suyos» (pág. 51 de la ed. cit.), había sido ya publicado anónimo, y con variantes, en la Séptima parte de Flor de Varios Romances nuevos, Madrid, 1595, fol. 40 v. ${ }^{21}$.

T E M A S

Este es, a grandes líneas, el panorama que ofrece en sus comienzos el romancero nuevo en Portugal, ceñida imitación de los modelos castellanos. En particular, podemos observar algunos aspectos que no hacen más que corroborar esa dependencia. Los temas, por ejemplo, como confirma Rodrigues Lobo, nláximo exponente entonces del romancero nuevo portugués, al acoger en su libro todos, o casi todos, los que habían puesto en boga los romanceristas castellanos. Los otros poetas citados limitaron más el campo de su temática.

a) Romances moriscos

Veamos primero el tema morisco, de tanto éxito en Castilla en la postrera década del siglo xvi y que en Portugal tiene un temprano cultivador en Agustín de Paredes, cuyos romances ya hemos visto. Por lo que se refiere a Rodrigues Lobo, en la "Carta aos Romancistas de Portugal" hace profesión de fe morisca, sacando a relucir todo el oropel y los convencionalismos que caracterizan el tema, explotado generosamente en buena parte de su libro:

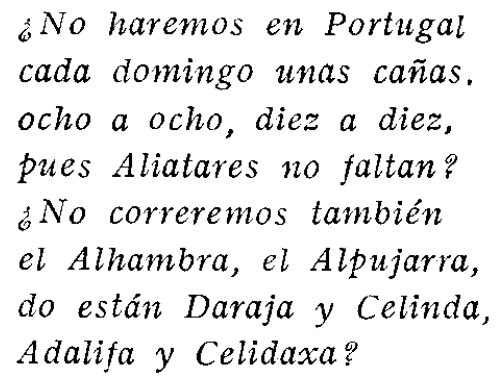

20 Antonio de Melo parece ser, como Agustín de Paredes, aunque sin tanta modestia, poeta misterio: su nombre no figura en ninguno de los repertorios bio-bibliográficos conocidos. Su moderno editor concluye: «Sólo podemos inferir, y esto por lo que su mismo libro nos descubre, que debió ser cortesano del Duque César de Este, y amigo de los ingenios que en la corte del mismo brillaron en Módena a fines del siglo xvi y comienzos del xvrI», pág. XI de la ed. cit.

21 Vol. IX de Las Fuentes del Romancero. 


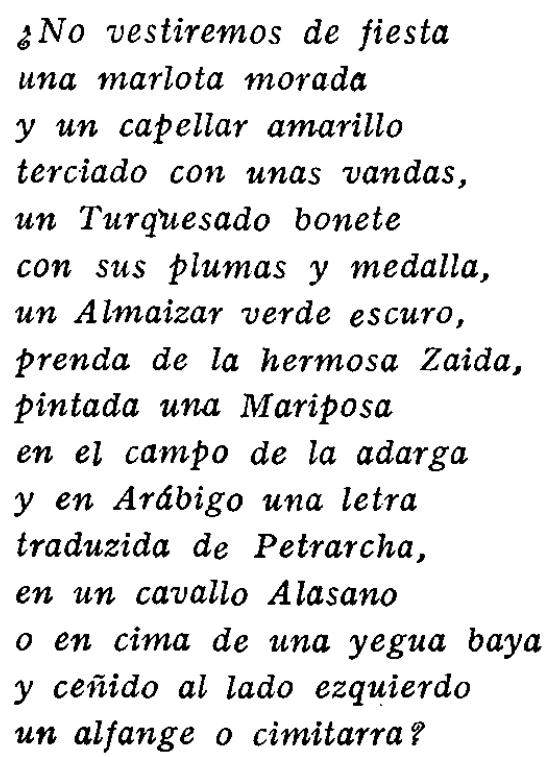

Son doce los romances moriscos de nuestro poeta ${ }^{22}$, más tres de cautivos ${ }^{23}$, cuyo parentesco con los de Góngora queda señalado en otro lugar ${ }^{24}$. A ellos pueden añadirse dos fronterizos de la guerra africana ${ }^{25}$, dedicados a la primera correría que hizo en Ceuta el marqués de Villa Real.

Nada nuevo que anotar en estas primicias poéticas de Rodrigues Lobo, que, a pesar de ciertas incorrecciones métricas, debidas principalmente a1 deslizamiento de algún lusismo cuando se trata de texto en castellano, se mueve con una soltura no exenta de gracia y armonía, por lo que más

22 aVestido de verde escuro, / que mui claramente enseña» (pág. 25 de la ed. cit.), «En frente de una ventana / donde vio la hermosa frente» (pág. 28), aOyendo estava Celinda /: las quexas que Azarque ofrece» (pág. 30), «De amor se querella Azarque / y de su Celinda ingrata” (pág. 32), «No es honor de Almoradíes / que a un traidor, aleve, infame» (pág. 34), «El pecho abrazando en ira, / por los ojos centellando» (pág. 36), «Dexando ya la razón / vencida de sin razones» (pág. 38), «E1 Sol en medio del cielo / estiende su clara lumbre» (pág. 88), “Celidaxa, la más bella / de las moras españolas» (pág. 108), «Este humilde moro tuyo / tan sin razón agraviado» (pág. 110), «En la cumbre de una roca / que con sobervia amenaza» (página 112) y «El enamorado Tarfe, / criado en casa de Çaidas (pág. 149).

23 QQuando sobre roxas nuves / estiende Apolo sus crines» (pág. 41), «Quando las nuves espessas / los orizontes anublan» (pág. 44) y «Fortuna, firme en mis daños, / varia sólo en el tormentò (pág. 45).

24 J. ARes Montes: Góngora y la poesía portuguesa del siglo XVII. Biblioteca Románica Hispánica. Madrid, 1956, págs. 85-86.

25 «El fuerte Alcaide de Ceuta, / galán, discreto y valiente» (pág. 114) y «Con valerosos Christianos / el Marquez corre la tierrax (pág. 116). 
de uno de sus romances, moriscos o no, merecen salir del olvido en que yacen ${ }^{26}$. Cabe preguntarse aún, un poco ingenuamente, si se alude en ellos, como hacen otros autores de romances moriscos y pastoriles, a episodios sentimentales del poeta - tan joven en este caso- o de personajes contemporáneos. Esta posibilidad parece insinuarse, en cambio, en alguno de los cuatro romances moriscos de Antonio de Melo ${ }^{27}$, en los que no sería muy aventurado adivinar al propio autor bajo el nombre de Azarque, especialmente en los que llevan los números 16 y 17 , romances de ausencia o destierro de amor, uno de Castilla, otro de Lusitania. Insisto, sin embargo, en la desconfianza que suele inspirar el presunto contenido autobiográfico de la mayoría de tales romances, porque, como ya ha señalado José F. Montesinos, refiriéndose a los imitadores de Lope, "es increible el número de los [poetas] que se destierran voluntariamente, en verso al menos, para llorar junto a una ruina o riberas de un río amores imaginarios) ${ }^{28}$.

$\mathrm{Y}$ con este manojuelo de romances moriscos de Paredes, Rodrigues Lobo y Melo se agota, por el momento, es decir, mientras no se descubran otros, la veta morisca portuguesa en el período que estudio, porque en el siglo xvir otro Melo de más categoría, don Francisco Manuel de Melo, realizó, un tanto rezagado, una correría en campo musulmán, de 1a que restan cinco romances, probablemente obra muy temprana, pues en el resto de su copiosa producción romancística se muestra más al día en la elección de temas ${ }^{29}$.

26 Para un estudio de los Romances de Rodrigues Lobo, véase RICARDo JoRGE: Francisco Rodrigues Lobo, ensaio biográfico e crítico, en Revista da Universidade de Coimbra, 1913-1918, II-VII, particularmente el vol. III, págs. 752-776, y, sobre todo, MaRIA DE LouRdes BhLCHIOR PONTES: Itinerário poético de Rodrigues Lobo. Lisboa, 1959, págs. 245-310.

27 aMil géneros de vengaza / traza el indignado Azarque» (romance 4), "Advier. te, gran Almançor, / pues en todo tanto adviertes» (rom. 5), “Desterrado de Castilla, / en Paris Azarque mora» (rom. 15) y «Aquel moro conoscido / en la fértil Lusitanian (rom. 16).

28 Algunos problemas del Romancero nuevo, en Romance Philology, 1952-1953, VI, pág. 244.

29 Estos romances moriscos, agrupados en La Citara de Erato, págs. 82-87 de las Obras Métricas, Ireón de Francia, 1655, son : "Ya por la puerta de Filvira / saliendo va de Granada» (pág. 82), «Sobre la torre más alta / de los muros de Antequera» (pág. 83), “Texiendo está Celidaja, / la hermosa hija dei Rey» (pág. 85), «En el Peñón de los Vélez, / Vélez, corona del mar» (pág. 86) y “Á las iras de Belaja / se sacrificava Hacén» (pág. 87).

18 


\section{b) Romances pastoriles}

Son más numerosos los romances pastoriles contenidos en los libros citados. Era también éste el otro gran tema de moda, que seguía muy de cerca al morisco, hasta rebasarlo en la última década del siglo xvi, cuando las cuitas de Belardo y Riselo, esto es, de Lope de Vega y Liñán, se divulgan más intensamente ${ }^{30}$.

Más lírico que el morisco, más íntimo y remansado, sin correrías, plumas ni desafíos, el romance pastoril no es, empero, menos convencional ni, en el fondo, muy diferente. Todo se reducía poco más que a cambiar de traje y nombre; así lo declara Rodrigues Lobo en la tan traída y llevada "Carta aos Romancistas", después de haberles invitado a vestir el traje morisco y todo lo demás:

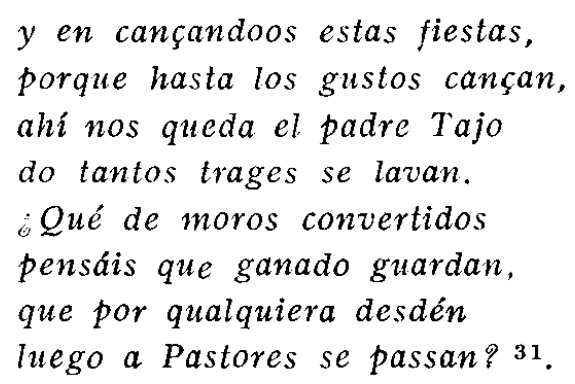

Ahora, los puetas, bajo el nombre de Delio, Tirreno, Lisardo, Sileno o Arsirio, entonan tristes arias de amor en un escenario rústico apenas

30 Vid. R. Mfińndez PIdal, : Romancero Hispánico, tomo II, Madrid, 1953, página 136.

31 Un ejemplo de paso a la inversa nos lo proporciona Antonio de Melo en el romance 2 de su Libro:

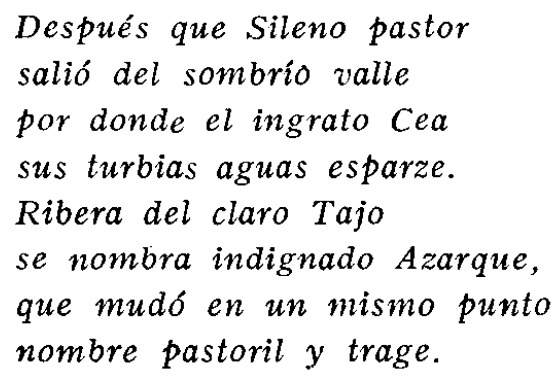

El primer verso de este ejemplo es, a todas luces, defectuoso por sílaba de más, y no creo que debido al autor, pues el libro está plagado de errores. En este caso, basta con una ligera transposición para que el verso quede perfecto, quizá como lo había escrito Melo: "Después que el pastor Sileno». 
descrito y siempre con unas mismas fórmulas ("A las sombras de un laurel", "Orillas de un claro río", "Por donde el claro Mondego", "Al pie de una seca peña), etc.), lamentos y suspiros que el viento llevará hasta la ausente, $y$ a veces ingrata, pastora.

Rodrigues Lobo se mueve mejor en el escenario y disfraz pastoril que en el morisco, y me refiero, claro está, a los romances, no a lo que vendrá después, que, ciertamente, no hará más que confirmar estos ensayos juveniles. Son catorce los romances pastoriles que contiene su libro ${ }^{32}$. Jiez pertenecen a un ciclo de Delio y Filena. Delio debe ser aquí el propio Rodrigues Lobo, como más tarde será Lereno en su trilogía novelística y aun, ahora, en un ejemplo de los Romances que señalaré. De los restantes romances pastoriles, uno, el portugués "Chorando lágrimas tristes), es de pastora. A1 grupo puede añadirse, por lo que tiene de rústico, un curioso romance de serrana que entronca con temas de la poesía tradicional: "A abrir las puertas del cielo / el Aurora se llevanta" (pág. 51).

Mousinho de Quevedo adopta el nombre de Tirreno en los cinco romances pastoriles de sus Rimas ${ }^{33}$. Como Lobo, como Brito y Melo y todos los que siguieron la pastoril senda, Mousinho pisa terreno conocido, sin descubrir nuevos paisajes ni hacer oir nuevas lamentaciones, "que - como dice en su romance I- el ayre lleva hasta el fuego / cercado de sus ovejas / qual de animales Orpheon. Pero es poeta delicado, que sabe expresar con bellos acentos el dolor y la tristeza de la soledad:

¿Qué viento turba la mar
de mi quietud soscegada?
¿Qué velo obscuro me cubre
el claro cielo del alma?

32 "Despierta de un dulce sueño, / abraçando sombras vanas» (pág. 54), "A las sombras de un laure1 / de que coronó las sienes» (pág. 56), "Dime, Silvio, pues la has visto, / ¿qué te pareció Filena?" (pág. 58), "Sentado sobre un pellico / al pie de un antigo lauro" (pág. 60), "Clara y pereçosa noche, / testigo de mis triste. zas» (pág. 63), "En la corteza de un frexno / que está mirando en las aguas» (página 65), "Filena, pues quando callo / hallo que de mí te aquexas» (pág. 67), «Al tiempo que el Sol dorado / bañava en el mar las riendas» (pág. 69), "Chorando lágrimas tristes / sobre huma esperança morta» (pág. 72), "Mirando al Sol de sus ojos / a la lumbre de la Luna» (pág. 138), "Mucho puede mi fortuna, / mucho su fuerça y intento» (pág. 141), "Detente, Belliza, un rato, / no huyas de mis querellas» (pág. 142), "Ante el perdido ganado / y ausente de su pastora» (pág. 151) y "Ay Belisa, qué recelos / son estos que me persiguen» (pág. 162).

33 «Ageno de sus plazeres, / no de pezares ageno» (romance I), «Mi esperança y mi ventura / contrarios effectos causan" (rom. II), "De las ya muertas cenizas / un nuevo fuego levanta" (rom. III), "Por alargar la cadena / a un cautivo pensamento» (rom. VI) y "Orillas del claro río / a do la torre de Alcides» (rom. VII). 


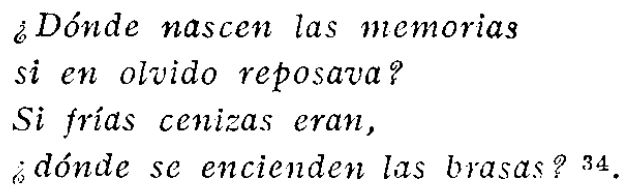

En cuanto a los diez romances de la Silvia de Lysardo, nueve son pastoriles ${ }^{35}$, muy conceptuosos, muy cortesanos y con finas notas descriptivas, que destacan a Brito entre sus compañeros de pastoraje; tal el romance que comienza :

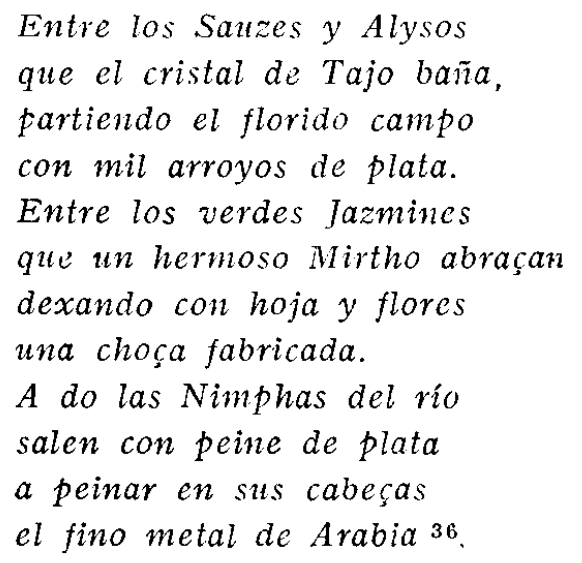

Por lo demás, ya se sabe : ausencias, desvíos, quejas o dilemas, como el de la "Carta que Lysardo mandou a Tarifa, pedindo-1he conselho se

34 Romance III.

35 «Dime, graciosa Tarifa, / ansí Dios guarde tu gracia» (fol. 34), «Gracioso Lysardo amigo, / Dios guarde tu buena gracia» (fol. 35), "Por donde el claro Mondego / con dulce corriente baxa» (fol. 36 v.), "Rodeado de Pastores / que lloran su muerte amarga» (fol. 37 v.), «Entre los Sauzes y Alysos / que el cristal de Tajo baña» (fol. 39), "Una candela en la mano / y un fuego vivo en el alma» (fol. 40), "Al pie de una seca peña / muy conforme a su cuidado» (fol. 41), "Las más altas sierras mira / el solitario Lysardo» (fol. 42) y «El ayre en niebla rebuelto, / el cielo escuro y nubladow (fol. 43).

36 Fo1. 39. Brito, o quien sea, deriva en seguida al fácil juego de palabras :

$$
\begin{aligned}
& \text { Prendadas tienen las manos, } \\
& \text { que son prendas regaladas, } \\
& \text { bueltos saetas los ojos } \\
& \text { y blanco entrambas las almas. }
\end{aligned}
$$

Y más adelante :

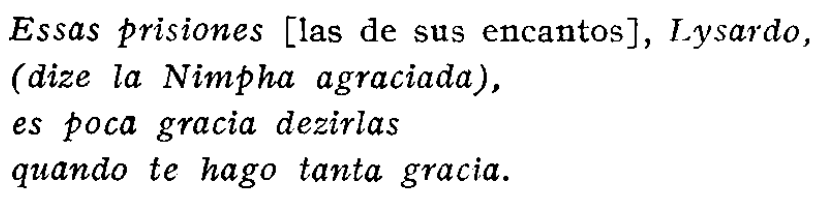


amaria a Silvia ou a Philis) (fol. 34). Philis, la de los ojos negros y gracia mesurada; Silvia, la de los verdes ojos y airoso talle. ¿Con cuál quedarse? ¿ Podrá acaso amar a entrambas a la vez? $\mathrm{Y}$ en otro romance, "Las más altas sierras miran, tras la consabida ambientación paisajística y afectiva del pastor, Lisardo, como Ronsard a Helena, advierte a la ingrata Silvia que el tiempo avaro le vengará de sus desdenes:

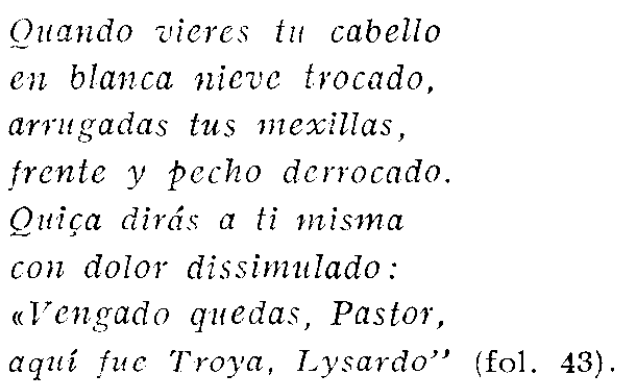

Aunque esto será imposible, se apresura a añadir el poeta, porque, como el tiempo vive en Silvia, él la irá renovando eternamente.

Antonio de Melo, Sileno unas veces y otras Arsirio, inciuyó nueve romances pastoriles en su Libro ${ }^{37}$. Pastor a orillas del Cea o del Pisuerga, no superó nunca, y rara vez alcanzó, a los otros poetas portugueses cultivadores del tema. Recordemos, sin embargo, entre esos romances, el 19, tal vez autobiográfico :

Alma inmortal de mi gusto,
gusto eterno de my alma,
divina imagen del Cielo,
milagro y gloria de Hespaña.

Desde Francia, el pastor recuerda a su amada Amarilis en la "dichosa Barcelona", y se ufana al decir que él tiene, aunque "embuelto en cuerpo francés, / alma y vida Catalanan. Es de notar asimismo el romance 7, que ofrece una transposición del mito de Orfeo al mundo pastoril.

37 «Quando el claro Dios de Delos / la fiera juba abrazava» (romance 1), “Después que Sileno pastor / salió del sombrío valle» (rom. 2), "Con un retrato en la mano / y en el corazón al vibo» (rom. 3), "Entre miserables riscos / cubiertos de plantas negras» (rom. 7), «Y a Pisuerga no me nombres, / pastor de tus bellas hijas» (rom. 8), "Aquel pastor fugitivo / desterrado de Pisuerga» (rom. 10), "Ingrato y ligero tiempo / que para el bien y el mal buelas» (rom. 11), “Alma inmortal de mi gusto, / gusto eterno de my alma» (rom. 19) y “Lágrimas tristes, salid, / porque descanse mi pecho» (pág. 114). 


\section{c) Romances piscatorios}

Variante del romance pastoril -compárase lo que ocurre con las églogas- es el romance piscatorio o marinero. El pastor se ha transformado en un pescador que se lamenta de los mismos padecimientos amorosos que apenan a los pastores. E1 escenario, ahora el mar o sus orillas, se describe también, como el rústico, muy brevemente. La contaminación o paso de un tema al otro es tan natural que en los romances de Rodrigues Lobo "Sobre as águas vagarosas / que o Tejo já traz cançadas" (pág. 144) ${ }^{38}$, y "Dende unas altas ruinas / que el tiempo va derribando / sobre las rubias arenas / que baña el sagrado Tajon (pág. 146), vemos al pastor Lereno que, buscando remedio a sus penas, ha trocado en vano el traje y oficio pastoriles por los de pescador.

Los romances piscatorios de Mousinho, bajo el poético nombre de A1meno, son nueve ${ }^{39}$, de variada calidad, pero dignos siempre y alguno bello y evocador, como el XIV :

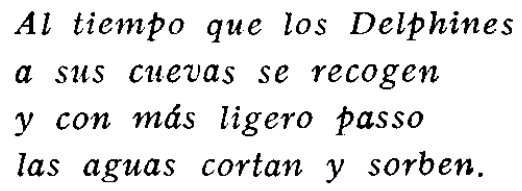

Sobre as águas vagarosas que o Tejo já traz cançadas de abrandar duros penedos $e$ de romper serras altas; perto donde o mar Océano lhe offerece livre entrada, dando às cristalinas ondas livres $e$ douradas prayas; lleva o pescador Lereno com rotas redes a barca, tam perseguida dos ventos quanto de amar sostentada; $e$ por que o leva forçado sua ventura contraria, desterrado do seu Lena $e$ de sua amada patria.

39 aIos ojos, los tristes ojos, / Almeno a la mar arroja» (romance XIII), «Al tiempo que los Delphines / a sus cuevas se recogen» (rom. XIV), «Al pie de un corvo peñasco / que sobre las olas cae» (rom. XV), "En las arenosas playas / de la sovertida Troya» (rom. XVI), «Al son de los leves remos / que blandamente 
Bello también, y quizá el mejor de todos sus romances portugueses, es el no numerado del folio 135 vuelto :

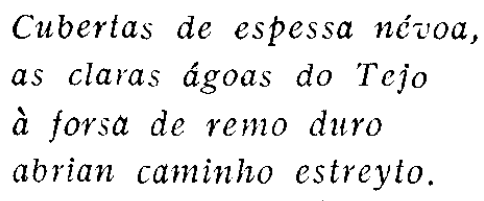

En él puede documentarse la influencia del tema de forzados, aunque aquí sea de amor, con un final que recuerda el de los romances de este tipo :

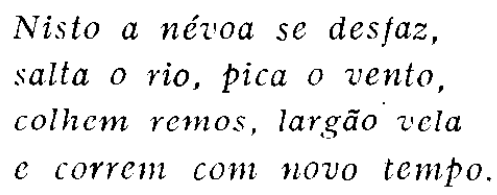

Aproximemos también al mundo piscatorio la versión "a lo marinero" del "Pranto de huma Senhora na morte de huma filha" ("De negro vistida toda, / cor que entre todas the agradan (fol. 133 v.), en el cual Mousinho presenta, en traje de "pobre pescadora", a una dama que llora la pérdida de su hija en el mar.

\section{d) Romances amorosos}

Otro tema abundantemente cultivado es el amoroso; el amoroso sin disfraz morisco, pastoril o marinero, pero sustancialmente lo mismo, con las mismas quejas e iguales cuitas, aunque algo más líricas en cuanto a que se prescinde casi por completo de los elementos decorativos rue aparecen en los otros. Pero la diferencia es muy sutil a veces, como ourre en los romances de Rodrigues Lobo "Armado para offenderse / por parte de seu cuidado" (pág. 156), y "Un galán y cortesano, / que es en gentileza y gracian (pág. 160), con pormenorizadas descripciones de indumento como en los romances moriscos y caballerescos. Aún así, se va imponiendo un lirismo libre de esos vínculos externos, que tendrá su gran difusión cntrado el siglo xvir, cuando moros $y$ cautivos han quedado arrumbados $y$ las quejas arcádicas dejan paso a los romances de aldea y a galanterías académicas.

conciertan» (rom. XVII), "El Sol iva declinando, / haziendo largas las sombras» (romance XVIII), "En vano dessea allivio / el triste que Amor persigue» (romance $\mathrm{XIX}$ ), «El codo sobre la arena / y recostado en el codo» (rom. XX) y "Remedio siempre de tristes / fue la querida esperançan (rom. XXI). 
Al lado de los dos romances acabados de citar, Rodrigues Lobo tiene otros más en consonancia con el patrón simplemente amoroso ${ }^{40}$, alguno burlesco, como "Señora, en llamaros Sol / mui mal Astrólogo he sido" (página 83), "Mira, Juana, que te digo / que no baxes a la calle) (pág. 85), contrahechura del lopiano "Mira, Zaide, que te aviso", y el bilingüe dialogado "¿Do bueno, señor Poeta, / que tan pensativo passa?» (pág. 124).

Los de Mousinho, siempre galantes y conceptuosos, se cargan de comparaciones y alusiones mitológicas; son romances de celos, de corazones robados, quejas y ausencias, en los que el poeta se dirige a su pensamiento o a las aguas del Mondego ${ }^{\mathbf{4 1}}$.

Melo, como siempre, gris, y utilizando el seudónimo de Arsirio, aunque sin revelar otra atadura con el mundo pastori1 ${ }^{\mathbf{4 2}}$.

\section{e) Romances históricos}

E1 tema histórico sólo atrajo a Melo, con cuatro romances de muy dudoso valor artístico: uno cidiano, "Mientras se apresta Ximena / con algunos de los suyos) (rom. 9); sobre Bernardo del Carpio otro, “Después que la injusta muerte / de su preso padre supo" (rom. 12), y los otros dos sobre la batalla de Alcazarquivir, "Está el bravo Sebastiano /

40 "Felicia, sem coração / pouco bastava a vencerme» (pág. 74), "¿Qué cielos de favor / son los que disbaratan», calcado sobre el romancillo de Juan de Salinas «¿Qué olas de congoxas / son estas que amenaza» (pág. 76), «Este venturoso hilo / do mi fe queda prendada» (pág. 79), «Venturoso papel mío / más que lo ha sido tu dueño» (pág. 81), “Engañada niña, / galana y discreta» (pág. 90), «Detente, engañado Apolo, / no apressures tanto el passon (pág. 122), “Quien de amor trata de burlas / sin que no burle de veras" (pág. 136) y “Memorias importunas, / enemigas crueles̀ (pág. 158).

41 «Romped, romped, duros celos, / el vientre de vuestra madren (rom. V), “¿Qué Ave me robó tan fiera / un hijo solo que tengo» (rom. VIII), «Dulce pensamiento mío / que vais con ligero buelo» (rom. IX), “Tardas, pensamiento, tardas, / y házesme el alma suspenssa» (rom. X), «Rompa mi lengua el silencio, / pues tanto el callar me daña» (rom. XI), «Agoas puras, cristalinas, / do Mondego claro e puro» (fol. 134 v.), “Ágoas puras do Mondego / te'gora a meus olhos puro» (folio 135), réplica del anterior, con cierta derivación «a lo divinon. Este no es el único caso de réplica «a lo divino» entre los romances de Mousinho; véase también la pareja “Junto a hum rio ao pé dhum freyxo / à sombra de verdes folhas» (folio 136 v.) y "Junto ao rio de seus olhos, / debayxo da fresca sombra» (fol. 137).

42 “Coraçon leal y noble, / mirad que en balde servís» (rom. 17), «Advierte, bella Amarilis, / pues quanto quieres adviertes» (rom. 18), «Tiempo yngrato y desleal, / ladrón robador de bienes» (rom. 20) y «¿Qué es esto, mi pensamiento? / ¿dónde están mis esperanzas ?» (rom. 22). 
en la Africana frontera" (rom. 13), y el tributo de las cien doncellas, "A los fidalgos Leoneses / el primer marqués de Astorgan (rom. 14).

\section{f) Romances mitológicos}

'Tampoco abundan los romances mitológicos, aunque sí las alusiones a dioses y mitos. Más arriba me referí a un romance pastori1 de Antonio de Melo contaminado por el mito de Orfeo; citaré ahora la contribuctin de Rodrigues Lobo, siempre inçuieto, al tema mitológico: un ronance sobre la muerte de Adonis, "Bucltas en nieve las rosas! que estrarzen el rostro bello" (pás. 101) y dos de Hero y I,eandro, "El pecho sobre las aguas / y los ojos en la torre» (páo. 103) y "Eil cuerp̣o muerto en la playa, / sobre la arena tendido» (pár. 106). El que comienza "Piblicó fiestas Cupido / el día de sant Cyruelon (pág. 119) es burlesco y coin 1nucho de nómina olímpica.

\section{g) Otros temas}

Poco cabe decir ya de otros temas. Entre los Romances de Rodrigues Lobo pueden espigarse tres satíricos de estudiantes - de la "vida scholástica) les llama él- ${ }^{\mathbf{4 3}}$ y uno soldadesco, gracioso por su ritmo e intención, "Juana de mis ojos, / pues que tocan caxa" (pág. 93), que recuerda el anónimo, también soldadesco, "Niña de mis ojos / que por gloria tie-

43 “En la humilde y pobre casa / que cubre su cuerpo hambriento" inág. 127). "Haze cuentas con su moço / un estudiante una tarde» (pág. 130) y "Un srámmatico estudiante / de los lindos de su tierran (pág. 133). Aunque no propiamente estudiantil ni de Rodrigues Lobo, pero sí relacionado con el ambiente universitario de Coimbra, es el romance de Mousinho " $\Lambda$ ham pretendente em Coimbra, perdendo huma cadeyra": "Como ciervo a quien cayó / de su frente la alta gloria» (rom. IV), en el que se increpa a Coimbra, comparándola a la fuente de Iipiro, que apaga las hachas encendidas y hace llamear las apagadas. Parece que este romance se refiere a algún suceso acaecido en aquella ciudad. ¿Al propio Mousinho?:

Puse por desdicha mía,

Coimbra, en tus manos mi honra,

$y$ manchástela de sangre

como de Joseph la ropa.

Siempre empeoras lo bueno,

lo malo siempre mejoras,

y con dañada ellectión

escoges como la loba. 
nes) ${ }^{44}$. Brito, en fin, incluye en la Silvia, como broche de sus nueve romances pastoriles, uno caballeresco, de Bradamante, con una primera parte descriptiva llena de color:

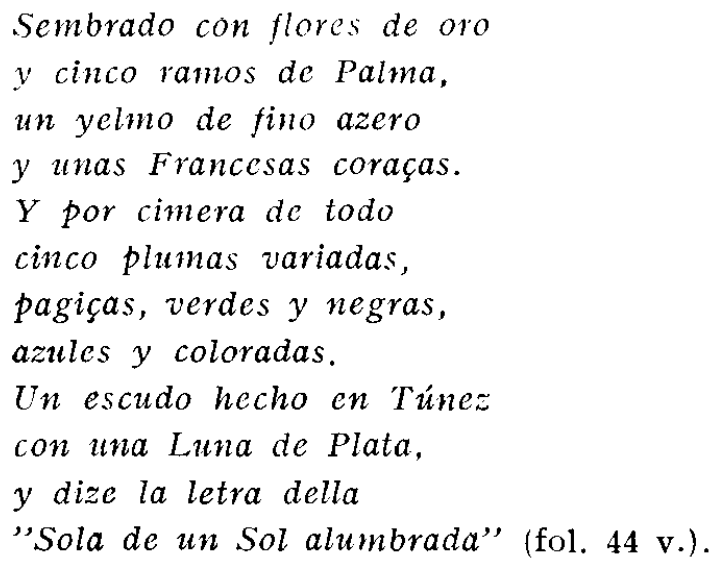

MORFOLOGÍA

En cuanto a la métrica, los autores estudiados no ofrecen ninguna particularidad que los diferencie de sus congéneres castellanos. Salvo cuatro ejemplos de Rodrigues Lobo, en los que se adopta la forma de romancillo hexasílabo, llamado una vez endechas ${ }^{45}$, y heptasilábico ${ }^{46}$, en el resto de sus romances, así como en los de los otros poetas, se utiliza siempre el octosílabo. Todos, excepto Agustín de Paredes y, en algún caso, Rodrigues Lobo, que agrupa a veces los versos de ocho en ocho, adoptan decididamente el movimiento cuaternario.

Siguiendo la moda impuesta por el romance para cantar, se insertan estribillos dispuestos tras cierto número de versos o cuartetas, repetidos las más veces regularmente ${ }^{47}$. Lo más frecuente es poner el estribillo cada

44 Tercera parte de Flor de varios romances. Madrid, 1593, fol. 127, vol. III de Las Fuentes del Romancero General.

45 «Engañada niña», «en endechas» (pág. 90) y “Juana de mis ojos» (pág. 93).

46 "Qué cielos de favor» (pág. 76) y "Mernorias importunas» (pág. 158).

47 Se dan casos de irregularidad; así, en el romance "Desde unas altas ruinas», de Rodrigues Lobo (pág. 146), la frecuencia del estribillo tiene lugar tras 24, 12, 12 y 16 versos; y en el romance 15 de Melo, la frecuencia es tras 20,16 y 12 versos. Irregularidad hasta cierto punto aparente, si pensamos, como ha señalado MonTEsrivos, en las exigencias de la melodía, que no era ya la tradicional, a que se sometían los romances para ser cantados: "Los estribillos, tan variados, venían a definir un tipo de composición que nada tenía ya que ver con otras desviaciones del romance, que va abandonando la métrica tradicional. Los estribillos acentuaban en el romance el carácter lírico, y reclamaban el canto [...]. El romance nuevo no 
ocho octosílabos: siete ejemplos sobre once en Rodrigues Lobo ${ }^{48}$; uno, en Mousinho, y, además, único caso de estribillo en sus romances ${ }^{49}$, y tres en la Silvia de Lysardo ${ }^{50}$. Pero también se repiten cada doce versos $^{51}$, cada dieciséis ${ }^{52}$ y hasta cada veinticuatro ${ }^{53}$.

E1 tipo de estribillo más abundante es el que se encuentra también con más frecuencia en las nueve partes de la Flor de varios romances: el formado por un heptasílabo y un endecasílabo:

buéliceme al duro remo,

que en el mayor peligro tengo el puesto 54.

Sigue el formado por dos endecasílabos:

Muera el falso Rugero, muera, muera,

saque mi braço el alma cruda y fiera ${ }^{55}$.

Los hay también de $5+11$ :

O tierra ingrata,

bien aya quien de ty lexos me aparta ${ }^{56}$.

De $8+11$ :

toma tus galas, tyrano,

déxame solo andar con mi ganado ${ }^{57}$.

se cantaba ni podía cantarse según las melodías tradicionales; se atenía ahora a los modos de una nueva música cortesana. El cambio de gustos flexibilizó el romance, acentuó su entonación lírica, adaptándolo a las exigencias de la música cortesana, a las exigencias del cantor." Algunos problemas del Romancero nuevo, página 237.

48 Páginas 41, 45, 63, 72, 142, 149 y 162 de la ed. cit.

49 "De negro vistida toda", fol. $133 \mathrm{v}$.

50 "A1 pie de una seca peña», fol. 41 ; "El ayre en niebla rebuelto», fol. 43, y "Sembrado con flores de oro", fol. 44 v.; estos dos con aparente irregularidad, pues el estribillo no aparece por primera vez hasta después de los versos 16 y 40 , respectivamente.

51 Romances de Rodrigues Lobo, págs. 76, 93 y 158.

52 Romance 11 de Antonio de Melo.

53 Romances 16 y 17 de Melo.

54 De Rodrigues Lobo, pág. 45. Otros ejemplos del mismo poeta, en las páginas $63,142,149$ y 158 . De Melo, romance 15.

${ }^{55}$ Silvia de Lysardo, fol. 44 v. Otros ejemplos: de Rodrigues Lobo, pág. 42 ; de Melo, romances 11 y 17 .

56 Romance 16, de Melo; de Lobo, pág. 162, y de Brito, fol. 43.

57 Silvia de Lysardo, fol. 41. 
De $7+6$ :

Vete conmign, entrañas, que tocan al arma 58 .

Hay un ejemplo de tres versos, $11+7+11$ :

Ay fortuna cruel, ay duros hados, que al fin de tantos años me daia a conocer vuestros engaños 59 .

y dos de estructura más compleja, de $7+7+7+11$ :

Ay enganosa glória,

ay difunta esperança,

que quando hum bem se alcança, já não fica do bem mais que a memória ${ }^{60}$.

y de $7+5+7+3$, que se aproxima al ritmo de seguidilla:

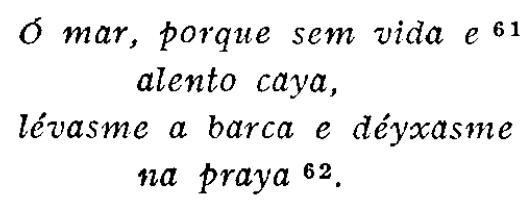

Otra particularidad que conviene señalar es la del romance con apéndice $o$, si se prefiere, la asociación al romance de una letra glosada, un soneto, octavas, redondillas, etc. Entre los romances citados se encuentran varios ejemplos de esta modalidad que a continuación indico. En la Silvia de Lysardo, al romance "Rodeado de Pastores" (fol. 37 v.) se agrega 11 soneto "E1 que se ve de amor más regalado" (fol. $38 \mathrm{v}$.). Soneto también - (Hermosa mano y llave de mis bienes" (pág. 140)— es el que liga con el romance de Rodrigues Lobo "Mirando al Sol de sus ojos" (pág. 138).

Otros ejemplos de distintas estrofas asociadas a romances de Lobo:

58 Rodrigues Lobo, pág. 93.

59 Ibid., pág. 146.

$60 \quad$ Ibid., pág. 72.

61 Así en el texto, consonando violentamente con el verso $3 .^{\circ}$, acaso por exi. gencia de la música y el cantor. ¿O se trata de un error de impresión? No hay duda que, trasladada al verso siguiente la conjunción «e», el ritmo sale ganando. al menos en la lectura.

62 Mousinho, fol. $133 \mathrm{v}$. 
al que comienza "Al tiempo que el Sol dorado" (pág. 69) se agrega la glosa a la letra antigua "Todos vienen de la vela / y no viene Menga); a "Sentado sobre el pellico" (pág. 61) se asocia una "Carta de Delio a Filena" en redondillas, mientras que son dos octavas las que acompañan al romance "Dexando ya la razón" ( jág. 38) y cuatro sextetos-rimas las ligadas a "E1 pecho sobre las aguas" (pág. 103).

Mousinho de Quevedo, fino glosador de cantares tradicionales ${ }^{6.3}$, se muestra muy aficionado a tales asociaciones, de las cuales su libro ofrece ocho ejemplos, todos de glosas a cantares propios o ajenos ${ }^{64}$.

CONCLUSIÓN

Espero que estas notas, a pesar de su forzada limitación, ofrezcan un panorama de lo que fue en sus comienzos el romancero nuevo en Portugal; algún día podrán completarse con nuevos hallazgos, que creo no modificarán en mucho mis conclusiones. Nació, como el romancero tradicional, del ejemplo castellano, pero si dependió de él en temas y formas también consiguió, en espíritu, tener, en algún momento, relativa vida independiente. En los libros de Rodrigues Lobo, Mousinho de Quevedo y Bernardo de Brito es posible recoger un ramillete de romances que, a pesar de todos sus tópicos, pueden competir en belleza y armonía con muchos de los que pueblan las páginas del Romancero General. Por 10

63 Entre estas composiciones destacan la logradísima glosa al cantarcillo ajeno «En la peña, sobre la peña, / duerma la niña y sueña», fol. 118 v., y la igualmente bella a «Soñava, madre, que vía / alegre mi coraçón, / mas los sueños, madre mía, / madre mía, sueños son», fol. 120. Otros cantares ajenos glosados: "Sin cuidados nascy yo, / ay Amor, ¿quién me los dio?», fol. 120 v., y “Prendióme el Amor, prendióme, / iay de mí!, / prendióme y dexóme ansín, fol. 121.

64 Romances XIII, XIV, XV, XVI, XVII, XVIII, XX y XXI. En la primera de las tres coplas castellanas de que se compone el apíndice del romance XVIII, se percibe - ¿a través de qué otra versión poética?, ¿acaso Garcilaso?- un eco de las quejas de Polifemo:

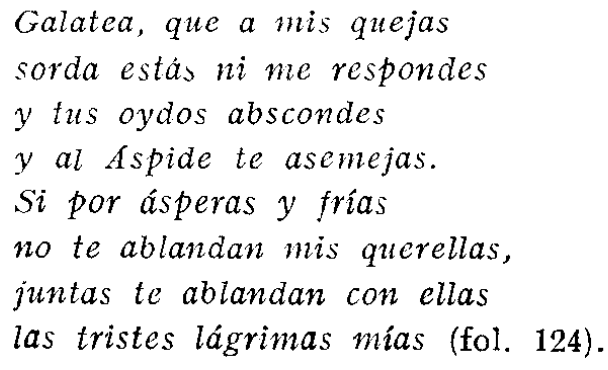


demás, en su evoluciọn posterior siguió el mismo camino del romancero nuevo castellano a lo largo del siglo XVII; y así vemos, por acotar sólo una parcela, cómo, en los libros que contienen romances, impresos en los primeros treinta años de aquel siglo, desaparece el tema morisco, con la ya indicada excepción de Francisco Manuel de Melo, y se diluye el pastoril, para dejar paso a otros temas, entre los que predomina avasalladoramente el amoroso, independiente de cualquier conexión morisco-arcádica, como en el Jardim do Ceo (Lisboa, 1607), de Eloy de Sá Souto Maior; en el Jardin de Apolo (Madrid, 1624), de Francisco de Francia y Acosta; en las Rimas Varias (Lisboa, 1628), de Antonio Alvares Soares; en las Varias Poesias (Coimbra, 1629), de Paulo Gonçalvez d'Andrada, y en los póstumos Divinos e Humanos versos (Lisboa, 1652, pero en gran parte, y en ella están incluidos los romances, de composición anterior a 1630), de Francisco de Portugal.

José Ares Montes 